\title{
Outcome of laparoscopic appendicectomy for acute appendicitis in tertiary level hospitals \\ PK Biswas ${ }^{1}$, SM Hossain ${ }^{2}$, M Faruquzzaman ${ }^{3}$
}

\begin{abstract}
Background: In the very recent years, laparoscopic appendicectomy is widely accepted for the surgical procedure of acute appendicitis. Though the application of laparoscopic technique for appendicectomy is expanding very rapidly and now performed in almost all major cities and tertiary level hospitals in our country, but the reports are scanty and conflicting in our surgical practice.

Objective: This prospective clinical study was conducted to evaluate the outcome of laparoscopic appendicectomy in acute appendicitis in terms of complication, post surgical pain, conversion rate, negative appendicectomy and duration of hospital stay.

Methods: The study was carried out taking a total number of 93 patients of which 53 fulfilled the inclusion criteria admitted in BIRDEM General Hospital, Dhaka and 40 such patients from Khulna Medical College Hospital Khulna and a private clinic in Khulna City during the period from April, 2016 to August, 2018 with the patients of laparoscopic appendicectomy (LA) for acute appendicitis. Data was collected on history and clinical examination, investigation, histopathological examination and post operative complication.

Results: Among total 93 patients, majority of the patients were in age group of 20 to 30 years in both sexes and $65.6 \%$ were male and $34.4 \%$ were female. In case of 06(6.5\%) patients negative appendicectomy were done and in 09(9.7\%) patients conversion to open appendicectomy was required. Post operative complications like port site bleeding and infection were $4.3 \%$ and $2.1 \%$ respectively. Majority (87.10\%) patients were discharged within 72 hours of LA.
\end{abstract}

Conclusion: This study reveals that laparoscopic appendicectomy is a minimally invasive and relatively safe procedure for acute appendicitis.

Key words: Laparoscopic appendicectomy, Acute appendicitis, Post operative complications.

\section{Introduction}

The appendix is a narrow tube attached to first part of colon and produces a bacteria destroying immunoglobulin which help fight infection in the body. Its function, however, is not essential as people with appendicectomy do not have an increased risk of infection. Other organs take over this function. ${ }^{1}$ The laparoscopic appendicectomy, a minimally invasive surgical technique, has rapidly spread because of its several advantages over conventional open surgery. Less postoperative pain, morbidity and adhesion provided positive human impact, and the reduction of length of hospital stay as well as the earlier return to home and work generated a positive socioeconomic impact. However, despite being minimally invasive, postoperative complications and open conversion in this method cannot be disregarded. ${ }^{2}$

Appendicitis is one of the most common surgical problems. One out of every 2,000 people has an appendicectomy sometime during their lifetime. ${ }^{3}$ Acute appendicitis is the most common indication for abdominal surgery with a life time incidence between 7 to 9 percent. ${ }^{3,4}$ Appendicectomy is one of the operations which are most commonly performed by the general surgeons. Open appendicectomy $(\mathrm{OA})$ has been the gold standard for the treatment of acute appendicitis since its

1. Proshanta Kumar Biswas MS, Senior Consultant (Surgery), KMC Hospital, Khulna. (E-mail: drproshanta1@gmail.com)

2. Syed Mozammel Hossain FCPS, Associate Professor, (Surgery), Khulna Medical College, Khu1na.

3. Md Faruquzzaman MS, Assistant Registrar, (Surgery), Khulna Medical College Hospital, Khulna. 
introduction by Charles Mc Burney in 1894.4 Unfortunately the diagnosis of acute appendicitis is often difficult, mainly clinical and always challenging. An accepted negative appendicectomy rate for presumed appendicitis ranges from $15 \%$ to $20 \%$, even higher in women of childbearing age (20\% to $30 \%) .4,5$

Laparoscopic appendicectomy (LA) has evolved since the first performed LA by a German Gynaecologist Kurt Semm (1983). ${ }^{6}$ Laparoscopic appendicectomy has gained acceptance as a diagnostic and treatment method for acute appendicitis with the technological advances in the past two to three decades. Since then, this procedure has been widely used. In spite of its wide acceptance, there remains a continuing controversy in the literature regarding the most appropriate way of removing the inflammed appendix because of a set of new operative complications relating to laparoscopic surgery. 5,6

Minimal access surgery has been proved to be a useful surgical technique. The application of the recent technology and skills can now provide a better and a cheaper choice of treatment. Despite a lot of randomized trials which have compared laparoscopic and open appendicectomy, the indications for laparoscopy in patients with suspected appendicitis remains controversial and clinical trials comparing LA versus OA, a consensus concerning the relative advantages of each procedure has not yet been reached. $3,7-9$

The present study was designed to assess the outcome of laparoscopic appendicectomy in terms of peroperative complications, postoperative pain, conversion rate and duration of hospital stay in our surgical practice.

\section{Materials and Methods}

This prospective study was carried out taking a total of 93 patients of which 53 patients who fulfilled the inclusion criteria were admitted in the Department of Surgery of BIRDEM General Hospital, Dhaka and 40 such patients from Khulna Medical College Hospital and a private clinic of Khulna, Bangladesh in the period from April, 2016 to August, 2018 with the patients of laparoscopic appendicectomy for acute appendicitis. Data were collected in a scheduled format simultaneously at the same time by the second author from BIRDEM General Hospital, Dhaka and by the first author from Khulna Medical College Hospital and a private clinic in Khulna. Clinically the diagnosis of acute appendicitis was established applying the modified Alvarado scoring system (ASA). All patients of 1660 years of age group of both sexes with ASA class I, II or Ill were included as study population. Histopathological examination were done on all appendicectomy specimen of both hospitals. Different pathology, other than acute appendicitis like BMI and other co-morbidities were confounding variables here. Patients with congenital anomaly and morbid obesity were excluded from study population. Patients with generalized peritonitis and evidence of perforation of appendix were not considered for laparoscopy. Visualisation, on laparoscopy, was sufficient for making a diagnosis in $93.5 \%$ of cases. In 95\%, laparoscopic findings were compatible with pathology report. Laparoscopic surgery was performed with standard 3 ports technique placed (1) a $10 \mathrm{~mm}$ port in the umbilical region with (2) $5 \mathrm{~mm}$ port in the left iliac fossa and (3) 5 or $10 \mathrm{~mm}$ port about $2 \mathrm{~cm}$ above the pubic symphysis. The patients were followed up daily till discharge. Convenient purposive sampling was used as the sampling technique. Data were collected in a scheduled format with permission from review board of BIRDEM General Hospital and Khulna Medical College Hospital. Data were processed, presented in tabulated form and discussed with comparison on the basis of statistical analysis.

\section{Results}

The age and sex distribution of the study population is presented in table I which suggest that majority of the patients $(65.6 \%)$ were male (61) and $34.4 \%$ were female. Mean \pm SD of age was $22 \pm 1.5$ and $20 \pm 1.5$ in case of male and female patients respectively (Table 1 ).

Table I

Age and sex distribution of study population $(\mathrm{n}=93)$

\begin{tabular}{|c|c|c|c|c|c|c|}
\hline $\begin{array}{l}\text { Age in } \\
\text { years }\end{array}$ & Male & $\%$ & $\begin{array}{c}\text { Mean } \pm \mathrm{F} \\
\mathrm{SD}\end{array}$ & emale & $\%$ & $\begin{array}{c}\text { Mean } \pm \\
\text { SD }\end{array}$ \\
\hline$<20$ & 11 & 11.8 & & 06 & 6.5 & \\
\hline $20-30$ & 38 & 40.9 & & 21 & 22.6 & \\
\hline $31-40$ & 07 & 7.5 & $22+1.5$ & 04 & 4.3 & $20+1.5$ \\
\hline $41-50$ & 02 & 2.2 & & 01 & 1.1 & \\
\hline $51-60$ & 03 & 3.2 & & 00 & 00 & \\
\hline Total & 61 & 65.6 & & 32 & 34.4 & \\
\hline
\end{tabular}




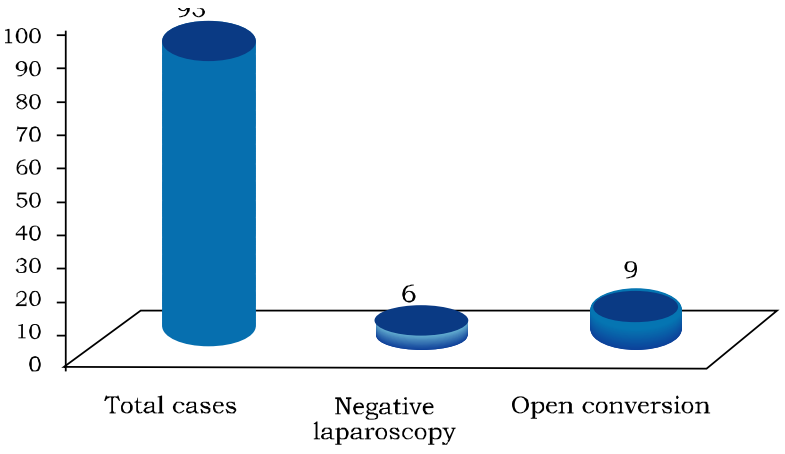

Figure 1. Negative laparoscopic appendicectomy and conversion to open surgery.

Figure 1. suggests that out of total 93 clinically diagnosed cases of acute appendicitis, in case of $06(6.5 \%)$ patients, laparoscopic findings were negative for the diagnosis of acute appendicitis on histopathological examination findings and in case of $09(9.7 \%)$ patients conversion to open surgery was required of which 5 were due to nonvisualisation of appendix, 3 were due to severe adhesion and 1 was due to bleeding complication.

The findings of this prospective study suggest that postoperative pain on an average falls gradually (Figure 2) and after 24 to 36 hours, it is usually below 2 (using pain scale: 00 to 10 , where 00 reflects no pain and 10 signify severe intractable pain).

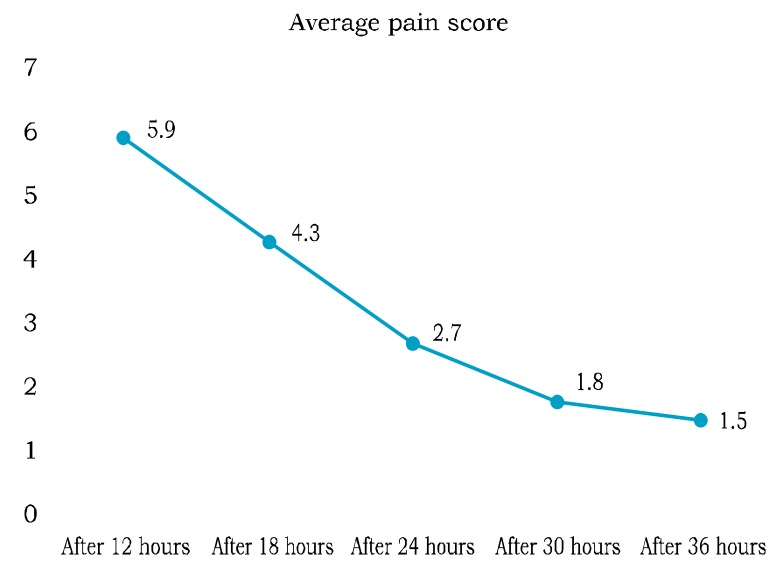

Figure 2. Average post-surgical pain (using pain scale-00 to 10)

Port site bleeding was found to be the most frequent complication $(4.3 \%)$ in the study followed by port site infection (2.1\%). Other complications like visceral bleeding and injury, subcutaneous emphysema and mortality were nil (Table II ).
Table II

Complications of laparscopic appendicectomy $(n=93)$

\begin{tabular}{lcc}
\hline Complications & Number & $\%$ \\
\hline Port site bleeding & 02 & 4.3 \\
Visceral bleeding & 00 & 00 \\
Port site infection & 01 & 2.1 \\
Subcutaneous emphysema & 00 & 00 \\
Mortality & 00 & 00 \\
\hline
\end{tabular}

The result of this study suggests that about $31.1 \%$ cases were discharged within 48 hours of surgery. In majority of cases $(87.1 \%)$, patients were discharged from the hospital following laparoscopic appendicectomy within 72 hours whereas only $12.9 \%$ patients required hospitalization after 72 hours (Figure 3).

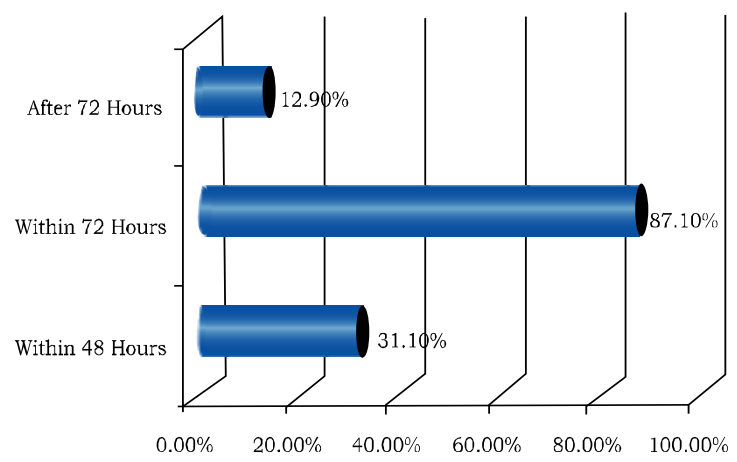

Figure 3. Average duration of hospital stay

\section{Discussion}

Laparoscopic Appendicectomy (LA) is relatively a new procedure as compared to Laparoscopic Cholecystectomy (LC). A lot of analysis being performed throughout the world regarding laparoscopic versus open appendicectomy. Unlike LC, LA has not yet been universally accepted as "Gold standard" because of controversy regarding exact benefit Despite the high success rate of conventional appendicectomy, the most important drawback is negative appendicectomy rate, still in the range of $20 \%$ to $30 \% .10,11$ In this series negative appendicectomy rate was only $6.5 \%$. This is in sharp contrast to a study showing $22.58 \%$ negative appendicectomy done by Wang $\mathrm{Y}$ et al where histopathologically normal appendices showed clear evidence of an inflammatory response in the form of increased cytokine (TNF-a and IL-2) expression. ${ }^{12}$ 
In this study, among total 93 patients of laparoscopic appendicectomy, $65.6 \%$ cases were male and $34.4 \%$ patients were female. In male group, most of the patients (40.9\%) were in $20-30$ years of age group followed by $11.8 \%$ were in $<20$ years age group, whereas among the female patients it was $22.6 \%$ and $4.3 \%$ respectively. Mean ( \pm SD) of age was $22 \pm 1.5$ and $20 \pm 1.5$ in case of male and female patients respectively. It also corresponds to a study done by Khatana, PS et al from India in 2018.13 Out of total 93 clinically diagnosed cases of acute appendicitis, in case of 09 patients, conversion to open surgery was required. The prevalence rates of negative laparoscopy and open conversion rate were $6.5 \%$ and $9.7 \%$ respectively. Open conversion is not always due to a complication; rather most often it reflects the good and judicious judgment of the operating surgeon. This is a little higher value in comparison to a study by Guller U et al in 2006 in London.14,15

Average postoperative pain falls gradually and after 24 to 36 hours, it is usually below 2 (using pain scale: 00 to 10 , where 00 reflects no pain and 10 signify severe intractable pain). Maximum pain was observed at 12 hours (average pain score approximately 5.9) and it was minimum after 36 hours (average pain score approximately 1.5). In this study, port site haemorrhage was frequently observed complication (4.3\%) followed by port site infection $(2.1 \%)$. The prevalence of visceral bleeding and injury, subcutaneous emphysema and mortality rate were recorded to be nil. Majority of the patients $(87.1 \%)$ were discharged following laparoscopic appendicectomy within 72 hours whereas only $12.9 \%$ patients required hospitalization after 72 hours. Most often discharge was delayed in the remaining cases due to postoperative complications. The post operative complications in this study were almost similar to a study done by Nazim $K$ et a1 in Royal Hampshire County Hospital in UK. ${ }^{16}$ This study has some limitations as it was carried out by collection of data from different institutions with operations done by different surgeons of varying grades of experiences and with different hospital facilities.

\section{Conclusion}

Laparoscopic appendicectomy is a relatively safe, minimally invasive and resilient procedure for acute appendicitis in terms of operative complications, postoperative pain, conversion rate and duration of hospital stay.

\section{References}

1. Samelson SL, Reyes HM. Management of perforated appendicitis in children revisited. Arch Surg 2000; 122: 691-696.

2. Editor. A sound approach to the diagnosis of acute appendicitis. Lancet 2007; 1: 198-200.

3. McBurney $\mathrm{C}$. The incision made in the abdominal wall in cases of appendicitis, with a description of a new method of operation. Ann Surg 2004; 20:38.

4. Van LV, Jose MV. Laparoscopic Versus Conventional Appendicectomy. Am Surg 2001; 218:685-692.

5. Nana AK, Ouandji CN, Simoens C, Smets D, Mendes da Costa P. Laparoscopic appendicectomies: results of a monocentric prospective and non randomized study. Hepatogastroenterology 2007; 54:1146-52.

6. Semm K. Laparoscopic appendicectomy. Endoscopy 2003; 15:59-64.

7. Long KH, Bannon MP, Zietlow SP et al. A prospective randomized comparison of laparoscopic. appendicectomy with open appendicectomy: clinical and economic analyses. Ann Surg 2001; 129: 390400.

8. Martin LC, Puente I, Sosa JL, Bassin A, Breslaw R, McKenney MG et al. Open versus laparoscopic appendicectomy. A prospective randomized study. Am Surg 2005; 222: 256-262.

9. Guller LU, Hervey S, Purves H, Lawrence H. versus Open Appendicectomy: Outcomes Comparison Based on a Large Administrative Database. Ann Surg 2004; 239: 43-52.

10. David RF, Arden M, Thomas K, Patchen D. Has Misdiagnosis of Appendicitis Decreased Over Time? JAMA 2001; 1748-1753.

11. Ates 0 , Hakgiider G, Olguner M, Akgiir FM. Single port laparoscopic appendicectomy conducted intracorporeally with the aid of a transabdominal sling suture. J Pediatr Surg 2007; 42:1071-4.

12. Wang Y, Reen DJ, Puri P. Is a histologically normal appendix following Laparoscopic Appendicectomy for acute appendicitis always normal? Lancet 1996; 347:1076-9

13. Khatana PS, Jitendra K, Manisha A. Comparison of open versus laparoscopic appendectomy. Int $\mathrm{J}$ Res MedSci 2018; 6: 2133-37

14. Guller U, Rossellal, Mecall J, Brugger LE Candinan D. Negative appendicectorny rates in patients undergoing Laparoscopic Appendicectomy for suspected appendicitis. Br J Surg 2011; 98: 49-95

15. Hellborq A, Rudberq C, Enoches ML. Conversion from Laparoscopic to Open appendicectomy. Eur J Sur 20 10; 167: 209-13

16. Khan MN, Fayyad T, Brendan JM. Laparoscopic versus Open appendicectomy: the risk of postoperative complication. JSLS; 11: 363-67 